\title{
Highly Fertile Intersectional Blueberry Hybrids of Vaccinium padifolium Section Hemimyrtillus and $V$. corymbosum Section Cyanococcus
}

\author{
Mark K. Ehlenfeldt ${ }^{1}$ and James J. Polashock \\ U.S. Department of Agriculture, Agricultural Research Service, P.E. Marucci Center for Blueberry \\ and Cranberry Research and Extension, 125A Lake Oswego Road, Chatsworth, NJ 08019
}

\begin{abstract}
AdDitional IndeX words. Vaccinium cylindraceum, V. arctostaphylos, V. smallii, V. yakushimense, $V$. hirtum
Abstract. The primary gene pool of Vaccinium species used by blueberry breeders has traditionally been the North American Vaccinium species of section Cyanococcus. Blueberries in commercial production represent three primary Vaccinium species and two ploidy levels. Significant use has been made of the secondary gene pool of Vaccinium, especially in the development of southern highbush blueberry (Vaccinium $\times$ corymbosum) cultivars. Section Hemimyrtillus species are distantly related and are best considered part of the tertiary gene pool of Vaccinium. Vaccinium padifolium, a member of section Hemimyrtillus and native to the Madeira Islands, Portugal, has features of notable value to conventional blueberry development, among these: upright structure, strong growth, abundant flowering and fruiting, good self-fertility, inflorescence structure suited to mechanical harvesting, and indeterminate/repeat flowering. Our objective was to incorporate germplasm from this section into cultivated materials and transfer the desirable traits these species possess for commercial production. We used $\boldsymbol{V}$. padifolium as a female in crosses with $V$. corymbosum and generated two highly fertile hybrids. These hybrids are intermediate in morphology, phonological, and their hybridity has been confirmed through DNA testing. These hybrids were used in further crosses to a variety of section Cyanococcus selections and have generated numerous second-generation hybrids. We have also determined by flow cytometry the ploidy levels of the hybrids and several previously unevaluated section Hemimyrtillus species.
\end{abstract}

Blueberries (family Ericaceae, species Vaccinium, commonly section Cyanococcus) are a diverse taxonomic group, and blueberries currently in commercial production represent three major Vaccinium species and two ploidy levels: $4 x$ $V$. angustifolium (lowbush blueberry), $4 x V$. corymbosum (highbush blueberry), and $6 x \mathrm{~V}$. ashei (rabbiteye blueberry). As such, these three types may be considered the primary gene pool of blueberry. Two other commercial types of blueberry are more distinctly true mixtures of species: half-high blueberry cultivars and southern highbush cultivars. Half-highs have been produced by hybridization of $4 x \mathrm{~V}$. corymbosum with $V$. angustifolium and retain a significant but variable percentage contribution from each species. Southern highbush cultivars have been developed by the introgression of the low-chillingrequirement species $2 x \mathrm{~V}$. darrowii into $4 x \mathrm{~V}$. corymbosum at contribution levels averaging $\approx 25 \%$. Several additional species from the secondary gene pool have also contributed small amounts of germplasm to named blueberry cultivars, among them $2 x \mathrm{~V}$. elliottii, $6 x \mathrm{~V}$. constablaei, and $4 x \mathrm{~V}$. tenellum.

Blueberry species are rather promiscuous, and as a result, most of the breeding of the previously mentioned species has been relatively straightforward. Diploid species often produce unreduced gametes at low frequencies that have allowed their use with cultivated tetraploid partners (Ortiz et al., 1992). Tetraploid and hexaploid species typically can hybridize freely but give rise to pentaploid hybrids. Often, the greatest difficulty

Received for publication 30 Sept. 2013. Accepted for publication 4 Nov. 2013. We acknowledge taxonomic advice and Vaccinium genetic resource material received from the U.S. Department of Agriculture, Agricultural Research Service, National Clonal Germplasm Repository in Corvallis, OR.

${ }^{1}$ Corresponding author. E-mail: Mark.Ehlenfeldt@ars.usda.gov. with interspecific offspring has been reduced fertility resulting from the production of odd-ploid hybrids (e.g., pentaploids from $6 x \times 4 x$ crosses). The ability to transfer germplasm through conventional crosses led Hall and Galletta (1971) to hypothesize a highly conserved basic genome in the genus Vaccinium. A problem of equal or greater importance in the breeding of exotic species hybrids is the recovery of fruit morphology that is neither too small nor too dark to meet commercial standards.

Section Hemimyrtillus AND its SPECies. Vander Kloet and Dickinson (1992) considered the species of section Hemimyrtillus to be the remnants of a once much more widely distributed taxon. Today, only six species occupy section Hemimyrtillus, and three of these are found in very limited localities. The species and their ranges are: $V$. cylindraceum (Açores, Portugal), V. padifolium (Madeira Islands, Portugal), $V$. arctostaphylos (Caucasus Region), V. smallii (Korea, Japan, Russia), V. yakushimense (Yakushima Island, Kyushu, Japan), and $V$. hirtum (Japan, South Korea).

The morphological feature that unifies Hemimyrtillus is a set of paired prophylls covering perenniating buds. In section Hemimyrtillus, the fused prophylls result in a distinctive, narrow bud, looking like a much-reduced, flattened nail of a bird claw. Vander Kloet and Dickinson (1992) also state that among species of section Hemimyrtillus, twigs are typically smooth or pitted (but not verrucose). In a morphometric study, Vander Kloet and Dickinson (1992) concluded that the western Hemimyrtillus species ( $V$. cylindraceum, $V$. padifolium, and $V$. arctostaphylos) could be shown to be distinct from the Northeast Asian section Hemimyrtillus. Similarly, an extensive DNA-based evaluation of Vaccinium species by Powell and Kron (2002) using nuclear and chloroplast markers supported this distinction and showed that the Northeast Asian 
Hemimyrtillus (V. smallii, V. yakushimense, and V. hirtum), and the "Tethyan" Hemimyrtillus (V. cylindraceum, V. padifolium, and $V$. arctostaphylos) form well-supported but separate clades, and led them to suggest that the Northeast Asian species should be removed from section Hemimyrtillus (Fig. 1). These Northeast Asian species appear more closely related to sections Praestantia and Oxycococcoides (Powell and Kron, 2002).

The following summation of these species is taken largely from Ehlenfeldt and Ballington (2012) and Vander Kloet and Dickinson (1992) and is supplemented with other sources and our personal observations.

Vaccinium padifolium, our primary species of concern, was first collected in 1777 by Francis Masson, an early plant explorer for the Royal Kew Gardens who transmitted specimens to Linneaus. $V$. padifolium is native only to the Madeira Islands and is typically found in sub-alpine shrubberies, degraded pastures, draws, and edges of coniferous (Coniferae) woods and pine (Pinus) barrens at altitudes from 1220 to $1700 \mathrm{~m}$. Plants are bushy to tree-like and typically 1 to $4 \mathrm{~m}$ tall. Under native conditions, plants possess an evergreen habit. In general, our specimens have tough, semiglossy leaves with a finely reticulated texture. Plants produce creamy, pink-tinged, bellshaped flowers that give rise to medium blue, ovate fruit. $V$. padifolium is notable for its profuse flowering, repeat flowering, and its high numbers of flower buds located on both young and old wood. Repeat flowering is a trait which, if introgressed into $V$. corymbosum, may allow multiple crops or continuous cropping. Vander Kloet termed the development of a floral axis outside a perenniating bud as it occurs in

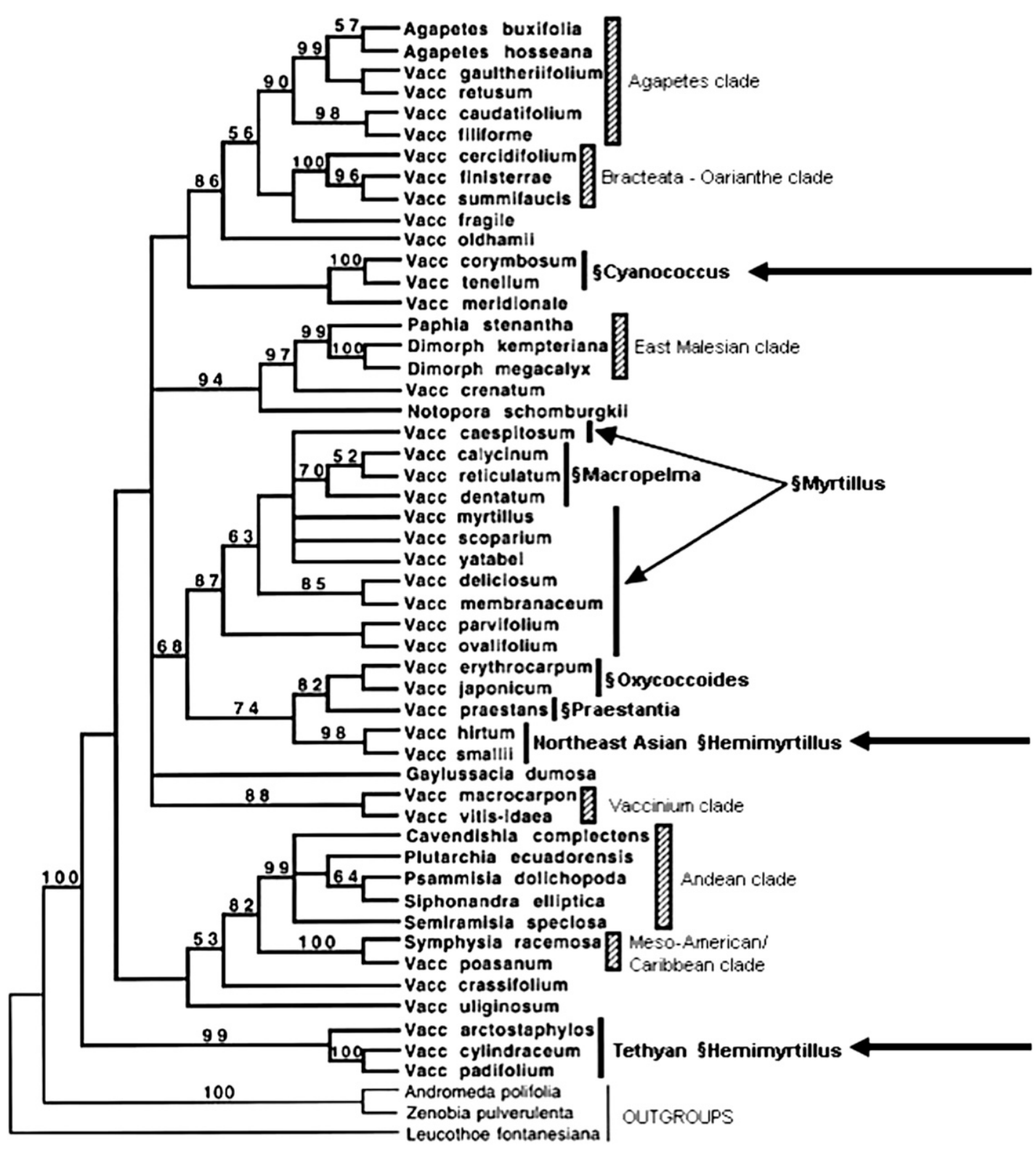

Fig. 1. DNA-based taxonomic tree of Vaccinium species of 50 species from tribe Vaccinieae and three outgroups from Powell and Kron (2002). Section Cyanococcus, Northeast Asian section Hemimyrtillus, and Tethyan section Hemimyrtillus are highlighted with arrows (reproduced by permission of the American Society of Plant Taxonomists). 
$V$. padifolium indeterminate flowering (Vander Kloet and Dickinson, 2005). Under our conditions, V. padifolium is insufficiently cold-hardy to thrive outdoors. The potted plants that we have kept under semiprotected conditions flower most typically in fall. Indeterminate flowering has implications in the season of flower bud development, the differentiation time of flowers within a bud, and the location of indeterminate flower buds (often developing from adventitious buds on older wood). Other useful traits include its general vigor, large mature plant size, excellent fertility, good fruit size, and general selffruitfulness. Its evergreen nature may be a useful trait under some conditions, but might also present management problems in terms of physiology and/or allowing the plants to be an insect or pathogen reservoir under field conditions.

Vaccinium cylindraceum is found natively on Faial, Pico, São Miguel, and Terceira Islands in the Açores, Portugal, on volcanic slopes of 350 to $1550 \mathrm{~m}$. Plants are drought-tolerant and succeed in neutral soils that are not too heavy (Trehane, 2004). Leaves are variable with some clones possessing relatively large, lance-shaped leaves and others having smaller leaves with a pronounced serrated edge. The leaves are tough, semiglossy, and have a distinct, net-like patterning. Plants flower in profusion and, like $V$. padifolium, both flowers and ripe fruit can be present on the plant simultaneously (Trehane, 2004). Flowers are typically deep pink at anthesis, fading to cream or white as they age. Flowers are cylindrical and elongated, hence the name $V$. cylindraceum. $V$. cylindraceum has a long inflorescence, primarily attributable to its long pedicels. This trait may be of considerable value for mechanical harvesting if it can be incorporated into commercial blueberries. Fruit is medium blue and ovate. A main difference between $V$. cylindraceum and $V$. padifolium is the deciduous habit of $V$. cylindraceum under native conditions. Under our conditions, $V$. padifolium appears more vigorous and more freeflowering than $V$. cylindraceum. Ploidy levels of $V$. cylindraceum and $V$. padifolium are unknown.

The third Tethyan Hemimyrtillus species, V. arctostaphylos, is a disjunct species with populations in Bulgaria, Turkey, and Anatolia as well as a relict population near the Caspian Sea. It is a mesophytic understory shrub found in open beech (Fagus) or oak (Quercus) woods as well as in coniferous (Coniferae) stands from 500 to $2400 \mathrm{~m}$. Plants are deciduous, 1 to $6 \mathrm{~m}$ tall, and have a relatively smooth bark. The selections of $V$. arctostaphylos that we have observed have finer (less coarse) and overall smoother leaves than the previous two species, but the texture can vary considerably. Flowering is less prolific than the previous two species, but like them, the plants may have a second flush of flowers (Trehane, 2004). Flowers normally have a distinct red coloration at anthesis that fades to shades of pink and cream. Its fruit is black, round, and glossy. $V$. arctostaphylos is a valuable complement to the other two species in that it has greater cold-hardiness, and it appears to have a tolerance to upland soils (Trehane, 2004). Ehlenfeldt and Ballington (2012) have indicated that it freely hybridizes with $V$. cylindraceum and $V$. padifolium. Darrow et al. (1944) determined a single specimen of $V$. arctostaphylos to be $4 x$. Together, the three species represent a considerable range of diverse and desirable germplasm.

Utilization value Of the Tethyan Hemimyrtillus SPECies. The earliest attempt to use these species in the development of cultivated blueberry was Darrow and Camp (1945) who reported the cross $V$. australe $(=V$. corymbosum $) \times V$. arctostaphylos. They did not however subsequently report that any hybrids or advanced selections resulted. Ballington (2000) reported several intersectional crosses of $V$. cylindraceum with both $2 x$ and $4 x$ germplasm of section Cyanococcus and other sections. Ballington generated second-generation hybrids with $V$. corymbosum, several of which were grown under field conditions to observe their performance. These second-generation hybrids used only $V$. cylindraceum germplasm. The observed hybrids exhibited good fertility but were early flowering and often sustained frost damage.

The species of section Hemimyrtillus are more distantly related to commercial blueberry than many of the species previously used in breeding and almost certainly would be considered to be positioined in the tertiary gene pool. Powell and Kron (2002) taxonomically place them as being more distantly related to section Cyanococcus than is cranberry (Vaccinium macrocarpon) or lingonberry (Vaccinium vitis-idaea). Nonetheless, our objective in working with these species is to incorporate germplasm from this section into cultivated germplasm and transfer the desirable traits these species possess for mechanical harvesting and commercial production.

\section{Material and Methods}

Materials. Specific materials used are listed (Table 1). Unless otherwise noted, other cultivars listed in tables are commonly available commercial cultivars (e.g., 'Duke', 'Hannah's Choice', etc.).

Flow CYTOMETRY DETERMinATION OF DNA CONTENT OF PLANT NUCLei (C-value). Leaf material $\left(\approx 1 \mathrm{~cm}^{2} / 20\right.$ to $\left.50 \mathrm{mg}\right)$ together with leaf material of an internal standard (Vinca minor) with known DNA content was chopped with a sharp razor blade in $500 \mu \mathrm{L}$ of extraction buffer (CyStain PI absolute P buffer, catalog number 05-5502; Partec, Münster, Germany) containing RNA-se, $0.1 \%$ dithiothreitol (DTT), and $1 \%$ polyvinylpyrrolidone (ice cold) in a plastic petri dish. After 30 to $60 \mathrm{~s}$ of incubation, $2.0 \mathrm{~mL}$ staining buffer (CyStain PI absolute P buffer) containing propidium iodide (PI) as fluorescent dye, RNA-se, $0.1 \%$ DTT, and $1 \%$ polyvinylpyrrolidone was added. The sample, containing cell constituents and large tissue remnants of the sample and the internal standard, was then filtered through a $50-\mu \mathrm{m}$ mesh nylon filter. After an incubation of at least $30 \mathrm{~min}$ at room temperature, the filtered solution with stained nuclei was measured with the flow cytometer [CyFlow ML (Partec) with a green diode laser $50 \mathrm{~mW} 532 \mathrm{~nm}$ (for use with PI); software: Flomax Version $2.4 \mathrm{~d}$ (Partec)]. The DNA amount of the unknown samples was calculated by multiplying the DNA amount of the internal standard with the DNA ratio of the relative DNA amount of the unknown sample and the internal standard. Flow cytometry determinations were performed by Plant Cytometry Services (Schijndel, The Netherlands).

Crossing. In Fall 2009, several V. padifolium plants were observed to be flowering. These were crossed to other species, including those from section Hemimyrtillus that were also showing small amounts of flowering at this time. The potted plants of section Hemimyrtillus species were brought into a heated insect-free greenhouse and supplied with supplemental artificial illumination.

Most pollinations were made onto section Hemimyrtillus species, because other flowering pollen sources were fieldplanted plants. Crosses were made without emasculation, to 
Table 1. Plant materials used in Vaccinium section Hemimyrtillus investigations.

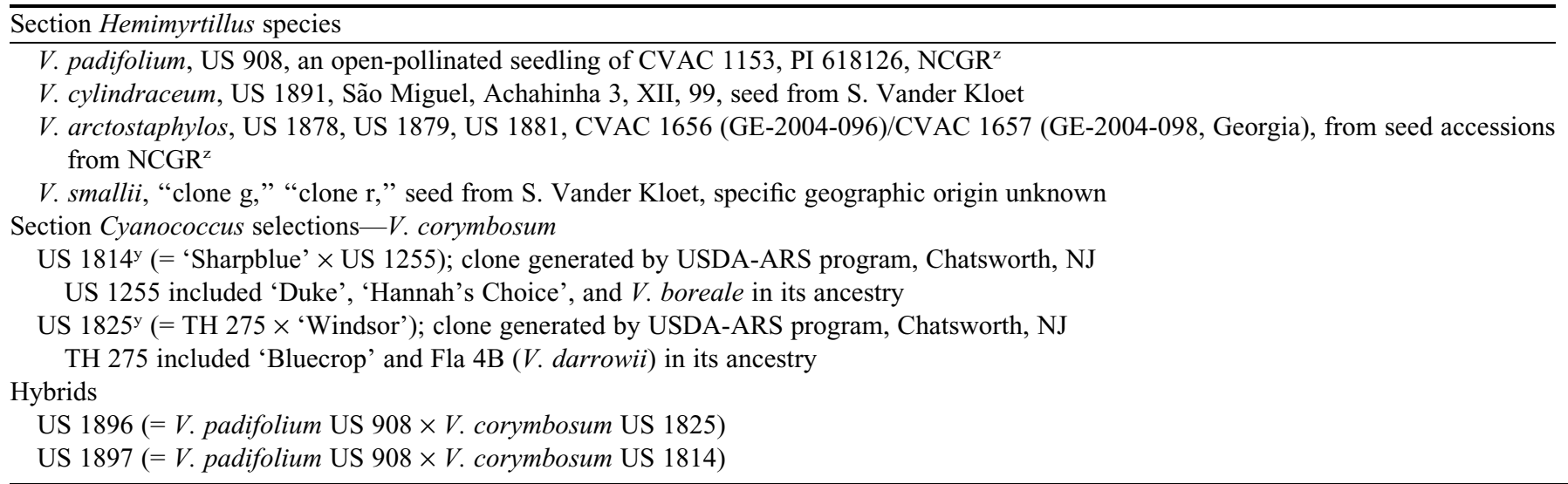

${ }^{\mathrm{z} U S D A-A R S, ~ N a t i o n a l ~ C l o n a l ~ G e r m p l a s m ~ R e p o s i t o r y, ~ C o r v a l l i s, ~ O R . ~}$

${ }^{\mathrm{y}}$ These two selections were clones resulting from one cycle of selection for indeterminate fruiting. Their immediate parents had expressed the trait to some degree as well.

disrupt the flowers as little as possible, with the recognition that selfing might also occur. We believed that selfs and hybrids would be sufficiently different morphologically to be recognizable.

For pollen, cut stems were taken from the field and put in vases in a heated greenhouse and pollen was collected from newly opened flowers over 1 to 2 weeks. Pollen, when not in use, was stored in glassine paper in a refrigerated dessication chamber. Pollen was applied with a sharpened pencil tip. Pollinations were made on what were judged to be mature stigmas.

Subsequent crossing was done primarily in Fall-Winter 2011-12.

Paclobutrazol treatment. Paclobutrazol (Bonzi ${ }^{\mathrm{TM}}$; Syngenta, Greensboro, NC) was applied once per week for 3 weeks as a foliar spray (100 $\mathrm{mg} \cdot \mathrm{mL}^{-1}$ a.i. to runoff) beginning in early September to promote floral bud development (Ehlenfeldt, 1998)

MoRPhOlOGY AND DNA fingERPRINTING. Morphological descriptions were based on the terminology and images of blueberry by Bailey and French (1946). Because sequence data are not yet available for $V$. padifolium, random amplified polymorphic DNA (RAPD) markers were used to fingerprint the parents (US 908, US 1814, US 1825) and the putative $F_{1}$ hybrids (US 1896, US 1897). The primers used were prescreened on the parents for the generation of reliable polymorphic bands ( $V$. padifolium vs. $V$. corymbosum). Those selected for final analysis were OPA-4, 7, 9, 10, 11, 12, and OPB-1. Primer designations are those of Eurofins MWG Operon (Ebersberg, Germany); however, all primers were synthesized by IDT (Coralville, IA). DNA was isolated using the CTAB procedure (Stewart and Via, 1993) as modified and described in Georgi et al. (2012). Polymerase chain reactions, polyacrylamide gel electrophoresis, and silver staining were as described (Novy et al., 1994). Reliable polymorphic bands were scored as 1 (present) or 0 (absent). Cluster analysis and tree generation using NTSYS-pc (Exeter Software, Setauket, NY) were as described (Polashock and Vorsa, 2002).

FerTility. Pollen was stained with acetocarmine jelly (75\% acetic acid with iron acetate) prepared according to the protocols/ recipe of Jensen (1962).

\section{Results}

\section{Flow cytometry}

Almost nothing was known regarding the ploidy of the section Hemimyrtillus species. We performed flow cytometric measurements of as much species material of the section as we could locate to address this issue. In our assays, the three Tethyan Hemimyrtillus species (V. padifolium, V. cylindraceum, $V$. arctostaphylos) were all determined to be $4 x$ with DNA content ranging from $2.39 \mathrm{pg}$ to $2.67 \mathrm{pg} / 2 \mathrm{C}$ (Table 2). In contrast, a single Northeast Asian Hemimyrtillus species tested, $V$. smallii, was determined to be $6 x$ with DNA content averaging of $3.86 \mathrm{pg} / 2 \mathrm{C}$. The two intersectional hybrids of $V$. padifolium $\times 4 x V$. corymbosum, whose generation we subsequently describe (US 1896 and US 1897), were also determined to be tetraploid with DNA contents of 2.51 and 2.54 $\mathrm{pg} / 2 \mathrm{C}$, respectively.

\section{Fertility and crossing of the parents}

FeMALE FERTILITY OF $\boldsymbol{V}$. PADIFOLIUM - US 908. Initial crosses were made in a screened, insect-free greenhouse under conditions in which $V$. corymbosum would not normally set spontaneous fruit. Therefore, we did not initially emasculate US 908 or our other $V$. padifolium clone, believing that minimizing handling stress caused by emasculation would optimize crosspollination success. Most crosses handled in this manner set fruit. Crosses were made with six different $V$. corymbosum selections and cultivars as males, most of which were used because they expressed some degree of fall flowering much like the indeterminate flowering of $V$. padifolium. US 908 flowered more prolifically, set more fruit, and produced more seeds/fruit than the other $V$. padifolium clone (Table 3 ). When this seed was planted out, many of the seedlings appeared to be selfs based on seedling color and leaf texture. All seedlings were retained, and ultimately only two appeared to be hybrids (Table 3). This is an estimated hybrid success rate of $0.008 \mathrm{seed} /$ pollination. Notably, one of the hybrids, US 1896, resulted from only three pollinations made with the pollen source US 1825 , whereas US 1897 resulted from 108 pollinations made with the pollen source US 1814 .

After the initial round of crossing, it was recognized that $V$. padifolium, as a species, and particularly our favored parental 
Table 2. DNA content and calculated ploidy levels of selected standards, section Hemimyrtillus species, and section Hemimyrtillus $\times$ Vaccinium corymbosum hybrids.

\begin{tabular}{|c|c|c|c|}
\hline Selection & DNA ratio with int. std. ${ }^{z}$ & DNA $\mathrm{pg} / 2 \mathrm{C}^{\mathrm{y}}$ & Ploidy \\
\hline V. darrowii BNJ 95-267-5 (2x standard) & 0.81 & 1.22 & $2 x$ \\
\hline V. corymbosum 'Duke' ( $4 x$ standard) & 1.66 & 2.51 & $4 x$ \\
\hline V. ashei 'Powderblue' ( $6 x$ standard) & 2.60 & 3.93 & $6 x$ \\
\hline V. cylindraceum US 1891 & 1.58 & 2.39 & $4 x$ \\
\hline V. arctostaphylos US 1881 & 1.69 & 2.55 & $4 x$ \\
\hline V. arctostaphylos US 1878 & 1.71 & 2.58 & $4 x$ \\
\hline US $1896=V$. padifolium $($ US 908) $\times 4 x V$. corymbosum $($ US 1825) & 1.66 & 2.51 & $4 x$ \\
\hline US $1897=V$. padifolium $($ US 908$) \times 4 x V$. corymbosum $($ US 1814$)$ & 1.68 & 2.54 & $4 x$ \\
\hline V. smallii "clone $\mathrm{r}$ " & 2.54 & 3.84 & $6 x$ \\
\hline V. smallii "clone g" & 2.56 & 3.87 & $6 x$ \\
\hline
\end{tabular}

${ }^{\mathrm{z}}$ Vinca minor internal standard with DNA content of $1.51 \mathrm{pg}$ DNA per somatic nucleus.

yPicograms of DNA in somatic (2C) tissue.

Table 3. Unemasculated crosses from 2009 producing verified $\mathrm{F}_{1}$ hybrids with section Hemimyrtillus species.

\begin{tabular}{|c|c|c|c|c|c|c|}
\hline \multirow[b]{2}{*}{ Cross } & Pollinations & Fruit & Seeds & Seeds/fruit & $\mathrm{F}_{1}$ & $\mathrm{~F}_{1} /$ pollination \\
\hline & \multicolumn{6}{|c|}{ 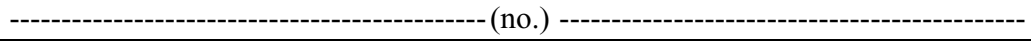 } \\
\hline Vaccinium padifolium $\times$ V. corymbosum (4 selections) & 148 & 22 & $65^{z}$ & $3.0^{\mathrm{z}}$ & 0 & 0 \\
\hline$V$. padifolium US $908 \times V$. corymbosum (5 selections) & 250 & 49 & $230^{z}$ & $4.7^{\mathrm{z}}$ & 2 & 0.008 \\
\hline
\end{tabular}

${ }^{\mathrm{z}}$ As a result of decayed condition of some fruit, some seed counts included in this total are estimates.

clone, US 908, was very fertile and set fruit spontaneously under greenhouse conditions. The high fruit set of $V$. padifolium appeared to be the result of the occurrence of cleistogamous pollination. Flowers of US 908 were observed to set fruit virtually $100 \%$ of the time, in the greenhouse when left undisturbed, and resulted in a few seed per flower. Flowers were observed to shed copious amounts of pollen and could be induced to release pollen before normal bloom by manual opening of the flower tips. Thus, many of our initial crosspollinations, which in retrospect would not be expected to be successful, resulted in small numbers of self-progeny.

In a second round of crossing, both unemasculated and emasculated crosses were performed as a comparison (Table 4). Flowers were emasculated at an early stage (when flowers were approximately three-fourths of their fully formed size). Among the emasculated flowers (greater than 500), many flowers aborted, and only 14 fruit were produced. These crosses averaged 2.4 seeds/fruit (s/f). Among unemasculated flowers $(\approx 170)$, there was a higher fruit set but a lower s/f ratio (1.8). During these crosses, $\approx 15$ emasculated flowers were left unpollinated. These unpollinated flowers failed to develop.

If only well-developed seed are counted, the results from the emasculated crosses translate into a success rate of $0.016 \mathrm{seed} /$ pollination (approximately double the value in our first pollinations but within the same order of magnitude). As of this writing, none of this second set of $V$. padifolium $\times V$. corymbosum seed has been verified as outcross hybrids. This low set supports the suggestions regarding the expected difficulty of this cross as well as the concerns voiced by Ehlenfeldt and Ballington (2012) of ability of non-identical pollen to grow viably down the long styles of these species.

MALE FERTILITY OF $\boldsymbol{V}$. PADIFOLIUM-US 908. Vaccinium padifolium (US 908) shed pollen profusely and cleistogamously as previously noted. Pollen appeared highly viable. Pollen grains in US 908 showed mostly normal tetrad structure with a small percentage $(\approx 5 \%)$ of grains being triads having one microspore of reduced size, often with a granular interior appearance (Fig. 2). US 1814 and US 1825 also were highly fertile (not shown).

A limited number of pollinations using US 908 as a pollen source onto four different $V$. corymbosum clones had variable results (Table 4). Some crosses of $4 x$ highbush $\times V$. padifolium failed. Across clones, crosses of $4 x$ highbush $\times$ US 908 resulted in seed set averaging $1.4 \mathrm{~s} / \mathrm{f}$; however, at this point, none of these have been verified as true hybrids. Crosses of US 908 with two non-highbush selections, 'Brunswick' ( $4 x$ lowbush) and NC 86-40-2 (6x V. constablaei), failed to set fruit.

\section{Parent and hybrid morphology}

Notable features of the mature V. padifolium clone, US 908, were very uniform, narrow elliptic leaves with narrow tip and basal angles, serrulate margins, and a leaf-to-width ratio approximating 2.3 (Fig. 3). Leaves had a relatively flat surface with fine leaf reticulation. US 908 possessed bell-shaped, cream-colored flowers (Fig. 4).

The $V$. corymbosum parents varied, but both possessed relatively small leaves (possibly as a result of $V$. darrowii and $V$. boreale components in their respective backgrounds) (Fig. 3). US 1825 leaves were oval with a wide to very wide tip and basal angles. US 1814 leaves were ovate with a wide tip and basal angles. For both clones, leaf margins were entire with a slightly reflexed edge typical of much $V$. corymbosum. The average leaf-to-width ratio for both clones was $\approx 1.7$ indicating a relatively broader leaf. Leaf venation differed between the clones but was within the range typical of $V$. corymbosum. The $V$. corymbosum parents in both cases possessed white urn-shaped flowers with relatively small apertures (Fig. 4). 
Table 4. Cross-fertility of Vaccinium padifolium and $\mathrm{F}_{1} V$. padifolium $\times V$. corymbosum hybrids.

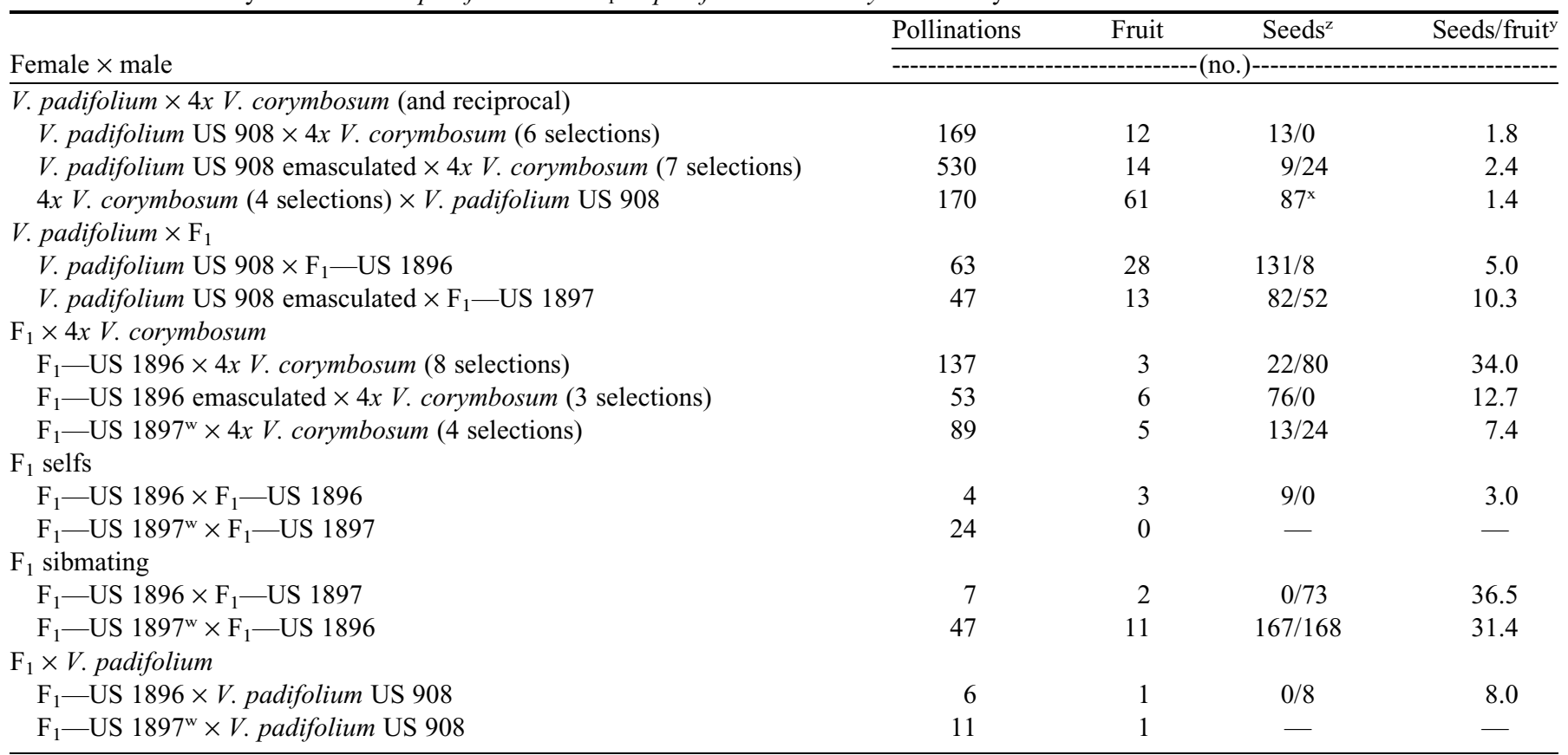

${ }^{\mathrm{z}}$ Seed counts represent counts of seed rated as good and good-fair in quality.

${ }^{y}$ Ratios were calculated using the sum of good and good-fair seed.

${ }^{\mathrm{x}}$ Seed of this cross combination were tallied only as viable (i.e., sum of good and good-fair).

${ }^{\mathrm{w}}$ Flowering was induced through the use of paclobutrazol.

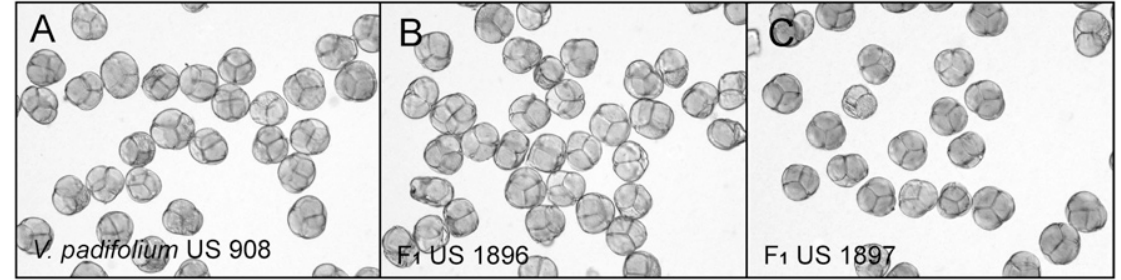

Fig. 2. Pollen of (A) US 908 (Vaccinium padifolium), (B) US 1896 ( V. padifolium $\times 4 x V$. corymbosum), and (C) US 1897 ( $V$. padifolium $\times 4 x$ V. corymbosum). All samples were stained with acetocarmine jelly $(75 \%$ acetic acid with iron acetate). Approximately $200 \times$ magnification.

to the two parents and a relatively smooth surface texture considerably more like $V$. corymbosum, especially that seen in southern highbush (Fig. 3). US 1896 flowered in late summer, and both flower trusses and flower morphology appeared intermediate (Fig. 4). The flowers were very slightly creamcolored. US 1897 was slow to flower, and paclobutrazol was used to induce flower bud development. The resulting flowers were similar to those of the $V$. corymbosum parent but more rounded with a relatively larger

Hybrids were intermediate in their morphology. Several notable features of selfs of $V$. padifolium vs. hybrid seedlings, even at a very young age (and recognized largely ex post facto), were strongly reflexed midribs, strongly serrulate leaves (especially for their size), textured leaves, and often slightly paler coloration. Despite the recognition of this character complex, the two $V$. padifolium $\times V$. corymbosum hybrids went through a considerable phase during which their morphology alone was not considered distinct enough to confirm their hybridity, although they appeared recognizably different from most other seedlings. As seedlings, they had less reflexed leaves and less serrulate edges. As more mature plants, the hybrids possessed leaf serrulation similar to the $V$. padifolium parent (Fig. 3). The leaves of both hybrids were narrow-elliptic like $V$. padifolium. US 1896 had narrow tip and basal angles and a length-to-width ratio of $\approx 2.6$. US 1897 had narrow tip angles, but wide basal angles and a length-to-width ratio of $\approx 2.3$.

US 1896 possessed a leaf surface and netting/reticulation similar to US 908, but less divided in appearance and distinct from the $V$. padifolium type (Fig. 3). US 1896 leaves were relatively coarse/thick. US 1897 had a leaf netting intermediate opening. Unlike the flowers of US 908, they were bright, pure white. The effects of paclobutrazol precluded any meaningful observations about truss structure. At this writing, the US 1897 hybrid has not gone through a natural flowering and fruiting cycle.

Fruit of US 1896 was deep blue with uneven waxiness and averaged $10.5 \mathrm{~mm}$ in diameter with a few fruit reaching diameters as large as $13 \mathrm{~mm}$ (Fig. 4). US 1897 fruit were black and somewhat smaller, averaging $9 \mathrm{~mm}$ but reaching as large as $14 \mathrm{~mm}$. Size appeared to be strongly correlated with seed set numbers (Ehlenfeldt and Martin, 2010).

\section{DNA fingerprinting}

Fifty-six RAPD markers were scored as polymorphic across the $V$. padifolium parent (US 908), the $V$. corymbosum parents (US 1814 and US 1825), and their putative $F_{1}$ hybrids (US 1896, US 1897). Approximately two-thirds of the markers scored in the hybrids were those of the $V$. padifolium parent, whereas approximately one-third were derived from the respective $V$. corymbosum parents (data not shown). A phenogram generated using these data shows the progeny grouping 


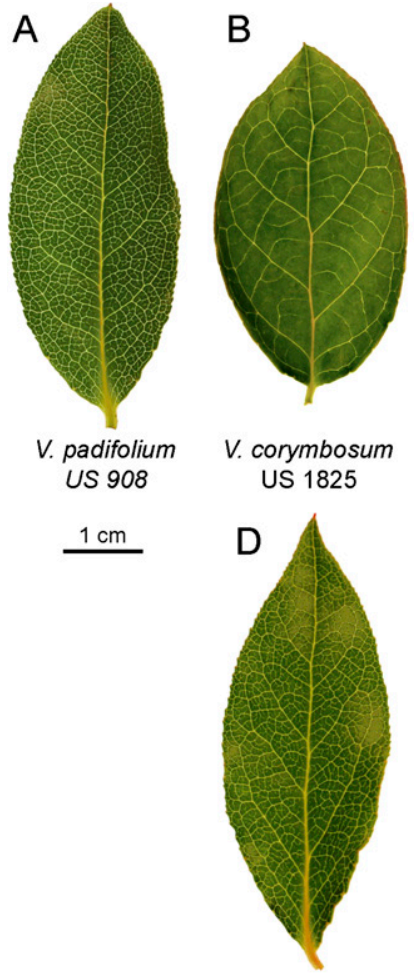

F1 US 1896
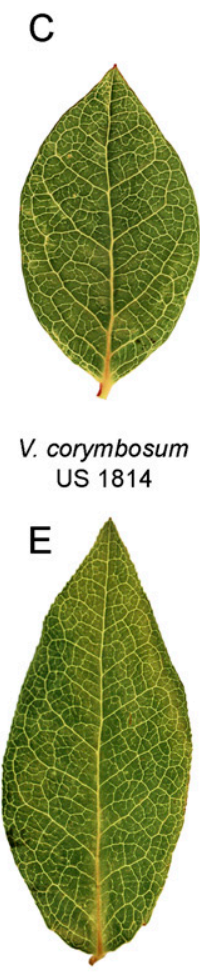

F1 US 1897

Fig. 3. Leaves of (A) US 908 (Vaccinium padifolium), (B) US 1814 ( V. corymbosum), (C) US 1825 ( $V$. corymbosum), (D) US 1896 ( $V$. padifolium $\times$ $4 x$ V. corymbosum), and (E) US 1897 ( $V$. padifolium $\times 4 x$ V. corymbosum). Images have been enhanced to accentuate venation.
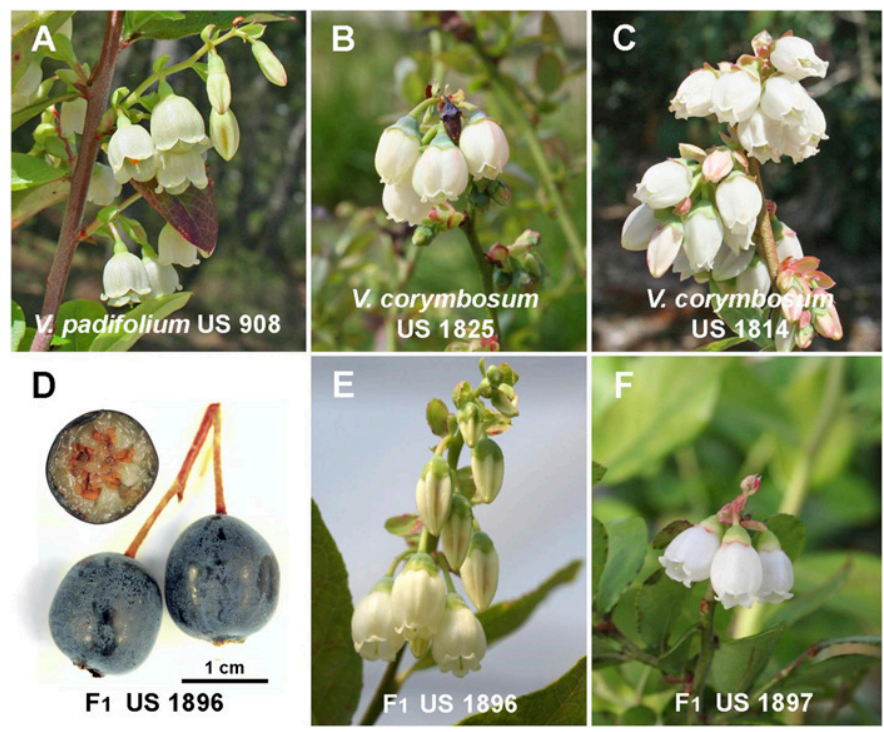

Fig. 4. Flowers (A-C and E-F) and fruit (D) of (A) US 908 (Vaccinium padifolium), (B) US 1814 ( $V$. corymbosum), (C) US 1825 ( $V$. corymbosum), (D) fruit of US 1896, (E) US 1896 ( $V$. padifolium $\times 4 x V$. corymbosum), and (F) US 1897 ( $V$. padifolium $\times 4 x V$. corymbosum).

most closely with the $V$. padifolium parent, whereas the $V$. corymbosum parents group most closely to each other (Fig. 5). RAPD markers tend to be dominant, but can be codominant, and their inheritance patterns are dependent on the state of the

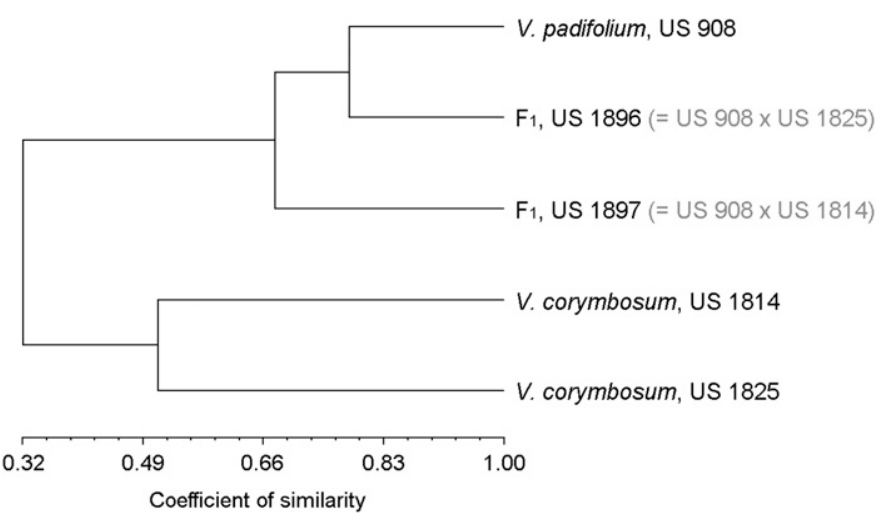

Fig. 5. Dendrogram showing genetic relatedness of Vaccinium padifolium, $V$. padifolium $\times V$. corymbosum hybrids, and $V$. corymbosum parents as generated using 56 random amplified polymorphic DNA markers.

parents. Given the high self-fertility observed in our crossing experiments, it is likely that the $V$. padifolium parent is more inbred (homozygous) and thus the majority of the selected markers in the progeny are derived from that parent. This may also reflect the fact that the hybrids are in $V$. padifolium cytoplasm. Nonetheless, the presence of $V$. corymbosumderived bands (scored bands not present in $V$. padifolium) supports the contention that these progeny are true hybrids.

\section{Female fertility of $F_{1}$ hybrids}

Female cross-fertility was assayed for both US 1896 and US 1897 , and much like the crosses with $V$. padifolium, initial pollinations were made onto unemasculated flowers.

US 1896 was successful as a female when pollinated by $4 x$ highbush (Table 4). In unemasculated crosses with eight different highbush selections, it produced an average of $34.0 \mathrm{~s} / \mathrm{f}$ and, in emasculated crosses with three selections, $12.7 \mathrm{~s} / \mathrm{f}$. Much like the case with US 908, when these latter seed were germinated, a number of the putative hybrids appeared little different from US 1896 and were presumed to be selfs. Among both of these groups of crosses, a number of hybrids occurred that appeared likely to be true hybrids based on their leaf morphology (i.e., tending toward highbush). Among these, many appear to express variegation, suggesting possible nuclearcytoplasmic incompatibility in advanced hybrids in $V$. padifolium cytoplasm (Correns, 1909).

The paclobutrazol treatments of US 1897 precluded completely reliable assessments of its female fertility; however, US 1897 also was successful as a female with $4 x$ V. corymbosum in unemasculated crosses, yielding low numbers (7.4) of s/f.

\section{Male fertility of $F_{1}$ hybrids}

As noted, US 1896 initiated a flowering cycle in the greenhouse in late summer/early Fall 2011. Flowering in the greenhouse in late summer is atypical for $V$. corymbosum, suggesting this hybrid possessed some level of indeterminate flowering character of $V$. padifolium. US 1897 flowered in the winter of 2012 as the result of the paclobutrazol treatment. Hybrids in both cases shed pollen profusely and pollen appeared to have high levels of stainability and viability. US 1896 and US 1897 displayed high fertility and, like US 908, had low levels $(\approx 10 \%)$ of triad formation (Fig. 2).

US 1896 was used as a male with a variety of blueberry selections and was successful in generating seed (Table 5). 
Table 5. Crosses of US 1896 ( $\mathrm{F}_{1}$ Vaccinium padifolium $\times$ V. corymbosum $)$ as male.

\begin{tabular}{|c|c|c|c|c|c|}
\hline \multicolumn{6}{|c|}{ Male: $F_{1}$-US 1896} \\
\hline \multirow[b]{2}{*}{ Female } & Pollinations & Fruit & Seeds & Seeds/fruit & \multirow[b]{2}{*}{ Comments } \\
\hline & \multicolumn{4}{|c|}{ 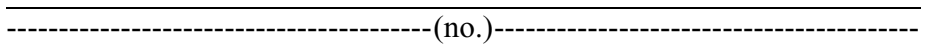 } & \\
\hline \multicolumn{6}{|c|}{$4 x V$. corymbosum (highbush) } \\
\hline Hannah’s Choice & 14 & 12 & 90 & 7.5 & \\
\hline \multicolumn{6}{|c|}{$4 x V$. corymbosum (highbush/southern highbush) } \\
\hline Cara's Choice & 57 & 45 & 603 & $13.4^{\mathrm{z}}$ & \\
\hline \multicolumn{6}{|c|}{$4 x V$. corymbosum (southern highbush) } \\
\hline Biloxi & 22 & 19 & 112 & $5.9^{\mathrm{y}}$ & \\
\hline Legacy & 135 & 82 & 1705 & $20.8^{z}$ & \\
\hline Sharpblue & 41 & 37 & 1388 & $37.5^{\mathrm{z}}$ & \\
\hline TH $622^{x}$ & 20 & 17 & 374 & 22.0 & \\
\hline \multicolumn{6}{|c|}{$4 x V$. angustifolium (lowbush) } \\
\hline Powderblue & 30 & 22 & 5 & $0.2^{\mathrm{z}}$ & Small seed, fair quality \\
\hline \multicolumn{6}{|l|}{$6 x V$. constablaei } \\
\hline NC 86-28-3 & 46 & 0 & - & - & \\
\hline NC 86-40-2 & 73 & 2 & 9 & 4.5 & \\
\hline US 831 & 12 & 0 & - & - & \\
\hline
\end{tabular}

${ }^{\mathrm{z}}$ Calculated on the 20 earliest ripening fruit.

${ }^{y}$ Calculated on the 15 earliest ripening fruit.

${ }^{x}$ TH 622 is a sibling of the southern highbush cultivars Camellia and Gupton.

Using US 1896 as a pollen source in $4 x \times 4 x$ crosses resulted in seed set ranging from $5.9 \mathrm{~s} / \mathrm{f}$ for 'Biloxi' $\times$ US 1896 to $37.5 \mathrm{~s} / \mathrm{f}$ for 'Sharpblue' $\times$ US 1896 . Interploidy crosses $(6 x \times 4 x)$ also succeeded at a low rate (ranging from $0.2 \mathrm{~s} / \mathrm{f}$ with 'Powderblue' to $4.5 \mathrm{~s} / \mathrm{f}$ with $V$. constablaei NC 86-40-2) (Table 5). US 1897 in pollinations with four $4 x$ highbush selections produced an average of $7.4 \mathrm{~s} / \mathrm{f}$.

\section{Selfing, sibmating, and backcrosses of $\mathrm{F}_{1}$ hybrids to $\boldsymbol{V}$. padifolium}

Modest attempts were made at selfing, sibmating, and backcrossing the $F_{1}$ hybrids (Table 4 ). Selfing appeared successful at a low level with US 1896, supporting our observation that unemasculated crosses of US $1896 \times V$. corymbosum might be producing self-progeny. Among sibmatings, the cross of US $1897 \times$ US 1896 appeared to produce qualitatively better seed than its reciprocal; however, s/f numbers were approximately equivalent $(\approx 30 \mathrm{~s} / \mathrm{f})$ if seed of both categories that we considered likely to be viable ("good" and "good-fair") were considered. These $\mathrm{F}_{2}$ progeny possessed excellent seedling vigor.

The hybrids could be backcrossed as males onto $V$. padifolium US 908 with relative ease and produced 5.0 and $10.3 \mathrm{~s} / \mathrm{f}$ for US 1896 and US 1897, respectively. The success of these backcrosses to $V$. padifolium buttress the proof of their hybridity in that these crosses had substantially better fruit set and better $\mathrm{s} /$ f ratios than comparable $V$. padifolium $\times V$. corymbosum crosses. Limited pollinations from reciprocal crosses $\left(\mathrm{F}_{1} \times V\right.$. padifolium $)$ prevent drawing any firm conclusions other than that these crosses could be achieved if needed.

\section{Discussion}

In this article, we report on crossing and incorporation of the Tethyan Hemimyrtillus species into cultivated blueberry (section Cyanococcus). These section Hemimyrtillus species are distantly related to cultivated blueberry, but possess valuable characters including high fertility and indeterminate flowering.

We elucidated the ploidy level of the Tethyan Hemimyrtillus species based on DNA flow cytometry; we showed that $V$. padifolium, $V$. cylindraceum, and $V$. arctostaphylos are all tetraploids. We also determined that at least one of the Northeast Asian section Hemimyrtillus species is hexaploid. Our flow cytometry studies verified and expanded the results of Darrow and Camp (1945) and clarifies the crossing results obtained by Ballington (2000). These determinations give further impetus to the suggestion of Powell and Kron (2002) that the Northeast Asian section Hemimyrtillus species form a taxonomic clade distinct from that of the Tethyan section Hemimyrtillus. Ehlenfeldt and Ballington (2012) reported successful crosses among Tethyan species of section Hemimyrtillus in agreement with this knowledge of ploidy levels. These authors similarly reported a putative hybrid of $V$. smallii (determined here to be hexaploid) with a $6 x$ rabbiteye-derived hybrid.

We produced $V$. padifolium $\times V$. corymbosum species at low frequencies and verified their hybridity by morphology and by DNA fingerprinting. Despite the apparent degree of unrelatedness suggested by molecular markers (Powell and Kron, 2002), the crosses with the Tethyan section Hemimyrtillus species succeeded more easily than might be expected. Ballington (2000) had previously noted the production of hybrids with $V$. cylindraceum but gave no indications of ease or difficulty of production. In our previous crossing attempts, we tried a number of crosses on limited flowers available of $V$. cylindraceum and $V$. padifolium, which did not succeed. Ultimately, when 
plants grew larger and more flowers were available, hybrids with $V$. padifolium were produced with only modest difficulty and the hybrids produced had excellent fertility. In tetraploid hybrids such as these, a significant degree of fertility resulting from allopolyploidy might be expected (Clausen and Goodspeed, 1925). A critical question for future use might be the subsequent degree of hybrid fertility on crossing to other $4 x \mathrm{~V}$. corymbosum cultivars.

We evaluated the fertility of the derived hybrids and found them to be male- and female-fertile. All three parents and both hybrids shed abundant, stainable pollen, indicating that meiosis in the parents and hybrids was regular. $F_{1}$ hybrids were interfertile on sibmating and readily produced vigorous offspring. We also crossed the hybrids as males to $V$. corymbosum selections and several other section Cyanococcus species [V. angustifolium (lowbush), V. angustifolium-V. corymbosum (half-highs), $V$. ashei (rabbiteye), and $V$. constablaei] with relative ease. These secondary hybrids, although as yet unverified, suggest that further manipulation of this germplasm will not be difficult. A limited number of putative progeny with $\mathrm{F}_{1}$ hybrids as females (and thus in $V$. padifolium cytoplasm) have exhibited variegation, suggesting possible nuclear-cytoplasmic incompatibilities when advanced hybrids reside in $V$. padifolium cytoplasm.

$V$. padifolium $\times \mathrm{F}_{1}$ hybrids could be made with relative ease. The quantitative aspects of these backcrosses to $V$. padifolium support their hybridity. These hybrids present another avenue for recombining and exploiting this germplasm, especially if it is desired to use other $V$. padifolium clones that were less successful in primary crosses.

The diversity of germplasm among section Hemimyrtillus species for adaptation and useful characteristics as well as the fact that hybrids have been produced among the three species of section Hemimyrtillus (Ehlenfeldt and Ballington, 2012) suggest that it should be possible to exercise considerable selection for adaptive and fruiting characteristics before incorporating this material into conventional $V$. corymbosum germplasm. If the other species in section Hemimyrtillus are not as easily incorporated with $V$. corymbosum as was $V$. padifolium, our initial hybrids are likely to be an important avenue for incorporation.

Several vital questions exist for this germplasm: 1) Will there be nuclear-cytoplasmic barriers to the development of this germplasm? 2) Will it be easy to recover or maintain desired traits in offspring? 3) What is the expression of desired traits under various regional climatic conditions? At this point, little is known about the expression of section Hemimyrtillus genes such as indeterminate flowering in mixed hybrids or the inheritance of these traits. We have many secondary hybrids, however, that should allow determination of these first two questions. Plants of our initial hybrids are being propagated for field testing under regional climatic conditions to answer the final question. Further evaluations of these breeding materials will promote use of $V$. padifolium germplasm in the cultivated blueberry gene pool.

\section{Literature Cited}

Bailey, J.S. and A.P. French. 1946. Identification of blueberry varieties by plant characters. Massachusetts Agr. Expt. Sta. Bul. No. 431.

Ballington, J.R. 2000. Collection, utilization, and preservation of genetic resources in Vaccinium. HortScience 36:213-220.

Clausen, R.E. and T.H. Goodspeed. 1925. Interspecific hybridization in Nicotiana II. A tetraploid glutinosa-tabacum hybrid. An experimental verification of Winge's hypothesis. Genetics 10: 278-284.

Correns, C. 1909. Vererbungsversuche mit blass (gelb) grünen und buntblättrigen Sippen bei Mirabilis, Urtica und Lunaria. Zeitschrift für Inductive Abstammungs- und Vererbungslehre 1:291-329.

Darrow, G.M. and W.H. Camp. 1945. Vaccinium hybrids and the development of new horticultural material. Bull. Torrey Bot. Club 72:1-21.

Darrow, G.M., W.H. Camp, H.E. Fischer, and H. Dermen. 1944. Chromosome numbers in Vaccinium and related groups. Bull. Torrey Bot. Club 71:498-506.

Ehlenfeldt, M.K. 1998. Enhanced bud production in highbush blueberry (Vaccinium corymbosum L.) in response to paclobutrazol. HortScience 33:75-77.

Ehlenfeldt, M.K. and J.R. Ballington. 2012. Vaccinium species of section Hemimyrtillus: Their value to cultivated blueberry and approaches to their utilization. Botany 90:347-353.

Ehlenfeldt, M.K. and R.B. Martin, Jr. 2010. Seed set, fruit weight and yield in highbush blueberry cultivars (Vaccinium corymbosum L.) 'Duke' and 'Bluecrop'. J. Amer. Pomol. Soc. 64:161-170.

Georgi, L., R.H. Herai, R. Vidal, M.F. Carazzolle, G.G. Pereira, J.J. Polashock, and N. Vorsa. 2012. Cranberry microsatellite marker development from assembled next-generation genomic sequence. Mol. Breed. 30:227-237.

Hall, S.H. and G.J. Galletta. 1971. Comparative chromosome morphology of diploid Vaccinium species. J. Amer. Soc. Hort. Sci. 96:289-292.

Jensen, W.A. 1962. Botanical histochemistry. Freeman, San Francisco, CA.

Novy, R.G., C. Kobak, J. Goffreda, and N. Vorsa. 1994. RAPDs identify varietal misclassification and regional divergence in cranberry [Vaccinium macrocarpon (Ait.) Pursh]. Theor. Appl. Genet. 88:1004-1010.

Ortiz, R., N. Vorsa, L.P. Bruederle, and T. Laverty. 1992. Occurrence of unreduced pollen in diploid blueberry species, Vaccinium sect. Cyanococcus. Theor. Appl. Genet. 85:55-60.

Polashock, J. and N. Vorsa. 2002. Development of SCAR markers for DNA fingerprinting and germplasm analysis of american cranberry. J. Amer. Soc. Hort. Sci. 127:677-684.

Powell, E.A. and K.A. Kron. 2002. Hawaiian blueberries and their relatives-A phylogenetic analysis of Vaccinium sections Macropelma, Myrtillus, and Hemimyrtillus (Ericaceae). Syst. Bot. 27:768779.

Stewart, C.N. and L.E. Via. 1993. A rapid CTAB DNA isolation technique useful for RAPD fingerprinting and other PCR applications. Biotechniques 5:748-750.

Trehane, J. 2004. Blueberries, cranberries, and other Vacciniums. Timber Press, Portland, OR.

Vander Kloet, S.P. and T.A. Dickinson. 1992. The taxonomy of Vaccinium section Hemimyrtillus. Bot. Mag. Tokyo 105:601-614.

Vander Kloet, S.P. and T.A. Dickinson. 2005. RAPD typification: Phenetic analysis of Vaccinium inflorescences. Bot. J. Linn. Soc. 148:445-457. 